\title{
The usefulness of academic performance feedback to primary and secondary schools
}

\author{
V SCHERMAN, ${ }^{1} B$ SMIT' ${ }^{2}$ AND E ARCHER ${ }^{3}$
}

\begin{abstract}
There has been an increased emphasis on providing schools with feedback on performance of learners with the aim of improving the quality of education. However, if feedback on learner performance is to be effectively used by schools, then it is important to understand what the informational needs of the schools are and whether schools can access the information. Thus, one research question is posed in this article namely: How can the current presentation of performance data captured in the school reports and feedback sessions be improved? The conceptual framework for the study draws on evaluation studies focusing on the use and usefulness of information. Methodologically, design research using mixed methods was employed. A needs analysis of what information was essential was undertaken. Six primary and secondary schools were purposively sampled to participate in the needs analysis from which the first prototype of the report and feedback sessions was developed. This needs analysis was comprised of interviews. The second phase included a sample of 22 primary and 21 secondary schools. Data for this phase was collected by means of Delphi questionnaires. The data was analysed using content analysis using a variety of coding strategies. One of the significant findings speaks to the view that schools felt the current content was appropriate but that individual school information could be included for the schools requesting additional information.
\end{abstract}

Keywords: use, feedback, design research, nominal group technique, DELPHI questionnaires, reports, feedback sessions, support.

Disciplines: education studies, further education studies, information studies.

\section{Introduction}

The quality of education has been a recurrent theme in the educational landscape. Part of the debate is the role of principals and teachers in making adequate decisions based on performance data of learners (Coe \& Visscher, 2002; Dunn, Airola, Lo \& Garrison, 2012; van Petegem \& Vanhoof, 2005). While different monitoring systems on learner performance may exist within the school, there may also be systems which are external to the school which could be used as a resource. School Performance Feedback Systems (SPFS) are information

1. Vanessa Scherman, is a senior lecturer in the Department of Educational Psychology, University of Pretoria, Tel: + 2712420 2498, vanessa.scherman@up.ac.za

2. Professor Brigitte Smit, is attached to the Department of Further Teacher Education, University of South Africa, Tel: +27 12991 3033, smitb@unisa.ac.za.

3. Elizabeth Archer is a researcher in the Department of Information and Strategic Analysis, University of South Africa, Tel: +27 12429 2035, archee@unisa.up.ac.za 
systems, developed external to the school that provide schools with information learner performance. The goal of such feedback systems is to maintain and improve the quality of education by identifying patterns of learner performance in terms of strengths and weaknesses so that revisions to current teaching programmes can be made (Dunn, et al., 2012). With this in mind, the objective of the research reported in this article was to explore whether the reporting format and feedback sessions within the primary and secondary school monitoring system is appropriate and whether improvements can be made.

\section{Contextual background of research project}

In 2003, the Centre for Evaluation and Assessment (CEA), at the University of Pretoria, South Africa, in collaboration with the Centre for Evaluation and Monitoring (CEM), at the University of Durham, United Kingdom embarked on this research project. The National Research Foundation (NRF), in South Africa, funded this project in order to investigate the possibility of adapting existing monitoring systems established in the United Kingdom to the South African context. The aim of adapting such monitoring systems was to provide information about the quality of education that learners receive, and more specifically, the extent of academic gains made to intervene timeously and effectively in learner development, through an effective feedback system.

The British CEM Research Centre has developed a number of monitoring systems for various stages of the United Kingdom's schooling system, of which the CEA chose two: PIPS (Performance Indicators in Primary Schools), implemented at the beginning of primary school, and MidYIS (Middle Years Information System) implemented at the beginning of the secondary school. PIPS and MidYIS were chosen because of the lack of monitoring systems in South Africa that focused specifically on the beginning of the primary and secondary school. PIPS was renamed the South African Monitoring System for Primary Schools Project (SAMP) for the South African context and MidYIS, the South African Secondary School Information System (SASSIS). The initial funding was earmarked for validation of the monitoring systems, which took place over a period of four years.

By 2007, additional funding was obtained and the research questions were refined to include suggestions for improvement of the feedback received by the schools. To this end, the following research question was posed: How can the current presentation of performance data captured in the school reports and feedback sessions be improved?

\section{Literature Review}

The notion of what constitutes educational quality has been researched by many scholars. In the context of the developing world, educational quality presents more complex issues given the increasing access to education and the associated demands that go hand-in-hand with an increasing inflow of learners into the schooling system. The call for educational quality is therefore a serious one.

The monitoring process aims to lead to informed decision-making and improvement strategies, given the complex embeddedness of societal systems such economics and politics (Gawe \& Heyns, 2004; UNICEF 2000). Generally, educational quality can be thought of in the following terms: schools being able to transform inputs into outputs (OECD, 2005), that the objectives identified have national and societal relevance (Scheerens, Glas \& Thomas, 
2003, UNICEF, 2000), fairness in the distribution of resources, as well as the value of the certificates received which verify that knowledge and skills have been mastered (Scheerens et al., 2003; UNICEF, 2000; van der Werf, Brandsma, Cremers-van Wees \& Lubbers, 1999).

The need for informed decision-making has been on the increase especially in light of the fact that schools are becoming more autonomous (Bosker, Branderhorst \& Visscher, 2007). Furthermore, research on the use of performance data of learners has shown that this can be an effective mechanism to improve learner outcomes (Dunn, Airola, Lo \& Garrison, 2013). Apart from the relevance on the classroom-level, data-driven decision making is proving to be an effective management tool on the school-level and beyond. The reason for this is that data-driven decision making implies the collection, analysis and interpretation of data to inform practice and policy within educational settings (Mandinach, 2012).

The aim of monitoring and providing information based on a monitoring system is to improve teaching and learning. Van Petegem, Vanhoof, Daems and Mahieu (2005) are of the opinion that there are a number of reasons for gathering performance data, namely, for information needs in terms of functioning and learner performance so that adequate decisions can be made, for accountability purposes and to stimulate discussions with stakeholders. Here a distinction is drawn between what data is, namely, objective facts with no meaning attached or information where the data is interpreted (Davenport \& Prusak, 1998; Light, Wexler, \& Heinze, 2004; Mandinach, Honey, \& Light, 2006). If schools and teachers are to use the data they receive as part of monitoring systems, they need to transform the data into information with which they can work effectively.

Feedbacks of research results, and the use thereof, are not new concepts and researchers have been grappling with these concepts for decades, especially in the field of evaluation (Kirkhart, 2000). Feedback on learner performance should be about particular qualities of learners (strengths and weaknesses), learners' work and how the learner can improve (Black \& Wiliam, 1998). For feedback of performance data to be effective, both positive and negative aspects need to be highlighted (Duke, 2002) in order to motivate recipients of feedback to fulfil educational purposes (Siebörger \& Macintosh, 2004). Evidence suggests that feedback can be as harmful almost as often as it can be helpful, which can have a substantial effect on the improvement of task performance (Coe \& Visscher, 2002). Very often it is not the information itself that is of importance, but instead the manner in which such information is mediated and conveyed (Brinko, 1993). In sum, the impact of feedback depends on the interaction between the feedback message, the nature of the task performed and situational variables (Coe \& Visscher, 2002).

Put differently, the type of information and how that information is presented plays a significant role in the manner that the information is firstly received, and secondly, utilised or used and then implemented. Visscher (2002) includes this component of 'use' as a central concept in the way in which he theoretically articulates school performance feedback systems. Here, use can be defined as the process of applying knowledge received toward either the solution of a problem or alternatively the attainment of a predetermined goal (Love, 1985). Furthermore, utilisation is thought of in terms of a continuum from direct use to mere informational purposes without resulting in actual use (Weiss, 1981). Utilisation in the context of this research refers to the process of applying received knowledge and information with the aim of finding a solution to a problem or the attainment of a predetermined goal (Love, 1985). The application of the information may include direct use (instrumental use), delayed use or diffused conceptual use (Beyer, 1997, Estabrooks, 1999, Love, 1985). 
The various notions of 'use' appropriate for this research are instrumental use, conceptual use and symbolic use. Instrument use is the concrete application of the research information in a specific and directed way (such as decision-making) (Love, 1985, Harnar \& Preskill, 2007). Conceptual use is about using the information for general enlightenment, which means that thinking about the feedback information may be changed, but does not result in action. Finally, symbolic use is when information is used to legitimise practice or defend a position and to persuade to lobby for resources (Beyer, 1997, Estabrooks, 1999, Harnar \& Preskill, 2007; Visscher, 2002). In sum, regardless of how the information is used, Weiss (1981) suggests that use should be studied in terms of what is used, who uses it, how immediate the use is and the effect of the use.

\section{Research design and methodology}

For this research, design research was employed which focuses on designing and exploring innovations to test particular interventions in order to support specific theoretical claims. The aim of design research is to understand the complex interplay between theory, designed artefacts and practice (The Design-Based Research Collective, 2003). Design research is iterative in nature (as reflected in Figure 1, adapted from Nieveen, 2009), with the aim of improving the reporting format and feedback sessions, in addition to improving the design principles (Nieveen, 2009).

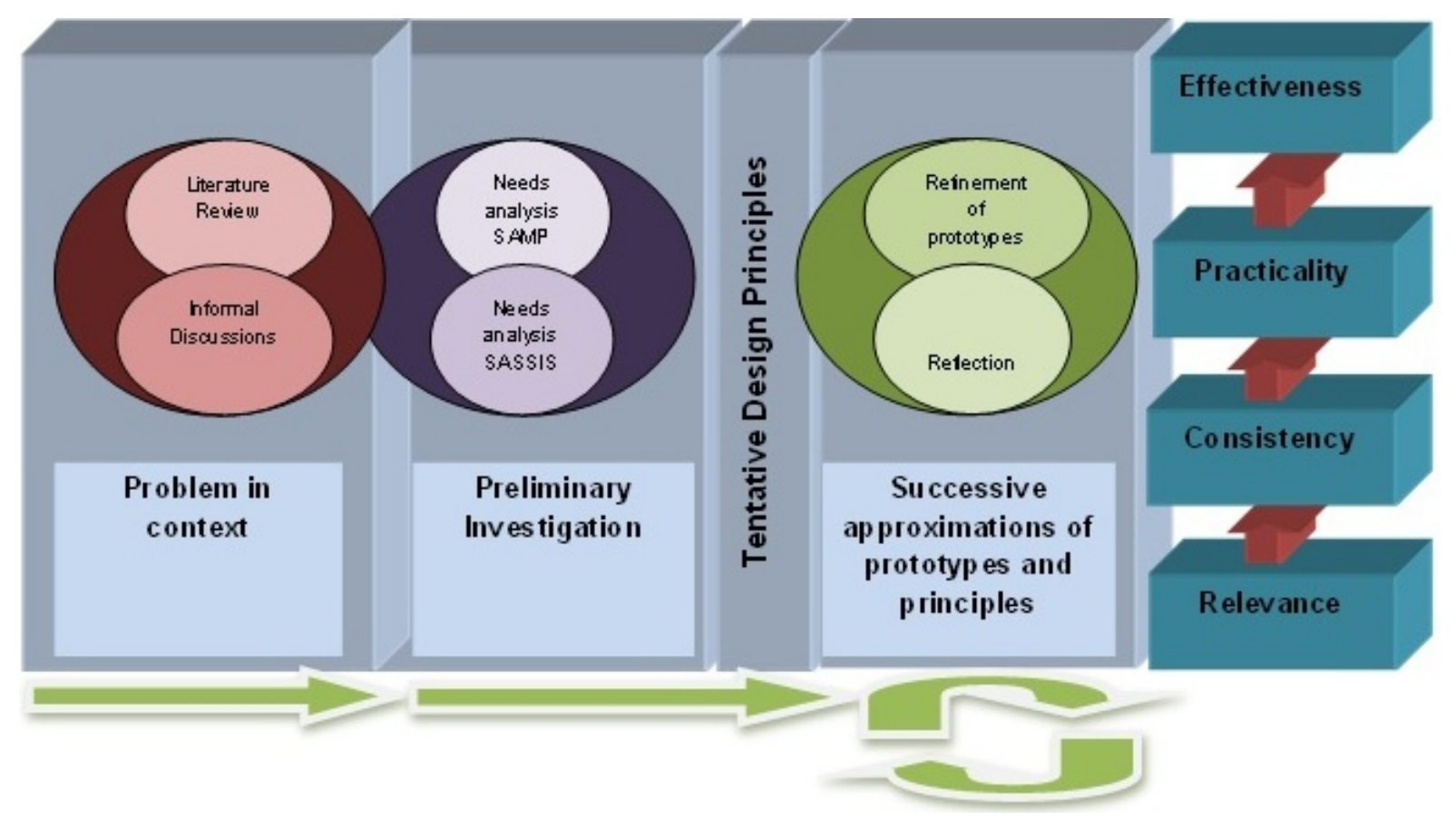

\section{Figure 1 Design research model}

The prototype, in the context of this discussion, is the report provided to schools, based on the performance data and the feedback sessions. The feedback sessions were arranged in consultation with the participating schools. The sessions normally took one and a half to two hours and included a presentation of the project, the assessment and the results overall. The 
schools were given an opportunity to discuss the research and ask questions, which is seen as a participatory process. Because of the rich information received, the sessions were recorded. At the feedback session, the schools were also provided with comprehensive reports which are tailored to their specific school.

Given the nature of the overarching project, the research was approached with an open mind in terms of using complementary methods. Both quantitative and qualitative methods were used to answer the identified questions. The typology chosen for the broader research project is QUAL $\rightarrow$ quan. The overall theoretical thrust to this design is inductive and was chosen due to the fact that a model of feedback is being developed. Both the qualitative and quantitative components of this study were kept distinct and methodologically independent, which implies that each is true to its own methodological assumptions (Morse, 2003). However, this article focuses specifically on the QUAL component of the study.

\section{Sample}

Several schools were purposefully selected to participate in this project for maximum variation in their characteristics and background. As the aim of the research is to develop a monitoring system, which would be appropriate for South African schools regardless of the variation in schools, it was imperative to include schools from various backgrounds. Due to financial constraints, a limited number of schools were accommodated in the sample, as discussed below.

The SAMP project sampled 22 schools, of which eight were English medium school, six schools were Afrikaans medium schools, seven Sepedi medium schools and one was a dual medium English/Afrikaans school. Two Grade 1 classes in each school undertook the baseline assessment. All 22 principals and selected heads of department and teachers were included in the study. While this article reports on the 22 schools that participated in the study, at the time there were schools who decided to withdraw.

For SASSIS, 21 schools were included. Instead of selecting schools according to language groups, SASSIS schools were selected according to previous department of education dispensation. The breakdown per previous dispensation was eight former Model $\mathrm{C}$ schools and Department of Education and Training, three Former House of Delegates and two House of Representatives. Two classes from every school were randomly selected ${ }^{4}$ by means of WinW3S. All 21 principals and selected heads of department and teachers were included in the study.

\section{Instruments}

In the main study, assessment instruments were used to assess the level of literacy and numeracy, but in this phase of the study only the feedback report, which contains the results is of relevance. For this phase, information was required on the current presentation and feedback sessions and thus drew on the interviews and DELPHI questionnaires.

4. WinW3S was used and it is a within-in school sampling package developed by the Data Processing Centre of the International Association for the Evaluation of Educational Achievement (IEA). Special permission was obtained to use the program as it is normally only used in IEA studies. 


\section{Interview schedules}

The aim of conducting interviews with principals was to collect data on what information related to the project that they felt was needed, as well as to probe how the reporting format and feedback sessions could be improved upon. The interview schedule was semi-structured in that although the questions had been formulated and the order determined, the order as well as the questions was able to be modified during the interview, as deemed appropriate. Working hand-in-hand individual interviews were the DELPHI technique.

\section{DELPHI questionnaires technique}

The DELPHI technique is a group problem-solving and decision-making tool (Michighan State University Extension, 1994). The technique is initiated by the posing of a specific problem to which participants anonymously make contributions. This phase is followed up by a series of carefully designed questionnaires which incorporate summaries and comments from the previous rounds to generate and clarify ideas. The process concludes with a voting process through which participants indicate the priorities for the specific project (Michighan State University Extension, 1994; Williams \& Webb, 1994; Dunham, 1996; Illinois institute of technology, ND).

\section{Data Collection}

This project started with a needs analysis of what information schools felt was essential to capture in the report and feedback sessions. Six primary and secondary schools participated in the first phase from which the first prototype of the report and feedback session was developed. The needs analysis comprised interviews with the principal, head of department and selected teachers from Grade 1 and Grade 8.

Twenty primary and 21 secondary were then included in the next phase of development. The Grades 1 and 8 learners completed the assessments, as part of SAMP and SASSIS in English, Afrikaans and Sepedi, depending on the language of instruction of the school. For both primary schools and secondary schools, a prototype report was generated and a feedback session held. During this session, schools received their reports, had the opportunity to ask questions and engage with the research team and the other schools. As the primary school feedback sessions took place first, a nominal group interview was arranged. However, due to difficulties experienced with the nominal groups in terms of attendance, a different method, the DELPHI technique, was used which essentially provided the opportunity to capture the same information as a nominal group.

The question posed to the SAMP and SASSIS project schools was: How can the feedback (reports and feedback sessions) from the SAMP/SASSIS project be improved? This question refers specifically to the following two aspects: the report and the feedback sessions, in terms of logistics and additional support provided so that the data could be interpreted and used effectively by the schools. However, schools were invited to also offer any other ideas pertaining to the programme.

The DELPHI technique was conducted through faxes to and from schools. The technique proved more appropriate than the nominal group technique with at least a third of schools in the sample contributing to each round of questioning. A great diversity of ideas was generated and discussed in relation to the feedback sessions, reporting and support for the projects. 


\section{Data Analysis}

Thematic content analysis is an analytical method that makes use of a set of procedures to draw valid inferences from text (Weber, 1985) or to analyse the content of text where the content refers to words, meanings and themes and where text refers to anything written, visual or spoken (Neuman, 1997). In this research, thematic content analysis was chosen for the analysis of curriculum documents and interviews because it provides the tools necessary for the chunking and synthesising of data for the creation of a new whole. Through this process, interviews and DELPHI questionnaire data that had been captured verbatim were coded according to different units of meaning (Henning, Smit \& Van Rensburg, 2004).

The analysis was facilitated through the use of a computer-aided qualitative data analysis programme, Atlas.ti (Scientific Software Development, 1997). Atlas.ti allows for the analysis of textual, graphical and audio data (Willig, 2001, p. 151) and facilitates the use of direct quotations to enrich the data representation. The use of computer-aided qualitative data analysis is specifically indicated when dealing with large amounts of unstructured textual material, which could cause serious data management problems (Henning et al., 2004, p.129). The tool also provides a platform for making the raw data, audit trail and process notes available, which facilitates trustworthiness of the data.

\section{Trustworthiness}

Validity in qualitative research is described in terms of the trustworthiness, relevance, plausibility, credibility, or representativeness of the research (Babbie \& Mouton, 1998; Lincoln \& Guba, 1985; Trochim, 2001). The validity of the research is located with the representation of the participants, the purpose of the research and the appropriateness of the processes employed (Winter, 2000). Validity for the qualitative component of this research has to do with the adequacy of the researcher to understand as well as represent the participants' meaning. Thus, validity becomes a quality of the knower in his/her relation to the data, enhancing different vantage points and forms of knowing (Tindall, 1990). Credibility is similar to the concept of internal validity (Lincoln \& Guba, 1985). It refers to procedures aimed at ascertaining whether the interpretations of the data are compatible with the constructed realities of the participants (Babbie \& Mouton, 1998). Peer debriefing and member checking (by means of the DELPHI process), is used in the process of this research. Validity in qualitative research is personal, relational, as well as contextual in nature. How the research was conducted was of importance in terms of whether the researcher was aware of her own perspective, processes, and the influence of these on the research (Marshall, 1986). Reflexivity, which is the examination of how one's own truth influences the research process, is also an important component of this research (Tindall, 1990).

\section{Findings}

One of the significant findings of this research speaks to how feedback can be used as a management tool. The reports provide a management tool as well as an opportunity in which discussion between heads of departments and teachers could take place at classroom level. The participants highlighted that the school's task is made more difficult due to combining special needs and mainstream schooling. Participants also indicated that the amount of information provided in the reports was overwhelming; for example, gender and class comparisons. They suggested that if this information is needed, it should be requested on a 
school-by-school basis. Principals suggested that feedback of school information should be clustered by school type as this would provide a more realistic picture and perhaps reflect more equally the demographics of the schools. However, as a positive, the participants indicated that they found the way in which data was shared with the school was empowering and would feed into their practice.

Schools indicated that the current content of the feedback session was applicable, but offered suggestions for further improvement. Schools who had been participants in the project for a number of years expressed a concern that they were familiar with much of the content of the presentation and that accommodation should be made for such schools. The schools expressed a need for more information on the assessment items so that educators would be better equipped to focus on learner preparation. The idea was mooted with a concern that such action would lead to teaching to the test behaviour. On the other hand the test would not be successful as learners will be prepared [specifically for the test]. (School 23, English, Round 2). A key concern from the researchers was that teaching to the test would take place and thus distort the purpose of the monitoring system. However, the aspect of understanding what would be expected of learner is important and thus materials linked to the content covered by the items were developed and given to schools.

The next finding focuses on the process, namely that feedback sessions be open to educators involved in the preparation of learners for primary and secondary schooling in the feeder areas. This will help [the previous years] educators to evaluate strength and weak areas in their teaching when looking at [preparing] the foundation [for primary and secondary] school (School 4, English, Round 2). Other schools expressed a preference for conveying information to the feeder schools and educators themselves as the feeder areas are often diverse. Some schools proposed a more interactive format for the feedback sessions. This would mean schools would facilitate some of the presentations themselves. This idea was acceptable to some schools, while others stated that the current discussion sessions allowed for valuable interactions. A third group of schools expressed concern that school facilitation would increase their workload.

Feedback session logistics also emerged as an important finding. The majority of participants expressed satisfaction with the current arrangements in terms of the timing of the feedback sessions, the venue and the directions to the venue. Whilst some principals indicated that they would like feedback sessions to occur earlier in the day, educators expressed concern that such a move would mean educators would not be able to attend. No [do not move feedback sessions earlier], we as educators cannot be there so early, our first responsibility is to the children in our classes. This may be possible for the principal to attend. (School 19, Afrikaans, Round 2). Although most schools were comfortable with the centrality of the current venue at the University of Pretoria for feedback, some indicated that it was a long journey. Suggestions were made for having more than one session focusing on the particular regions, possibly hosted by the participating schools. Individual feedback for each school was also suggested.

Reports are currently provided to each school and school level results are presented in comparative graphs where schools are represented anonymously. Schools with the same medium of instruction are thus able to make a comparison of results with other participating schools. However, concern was raised by one of the schools about these comparisons as it was felt allowing comparison could lead to friction. The overwhelming response to this aspect was that the comparison allows for an examination of the school level overall and provides 
valuable information. More than $80 \%$ of the schools supported the idea that schools be subgrouped during the comparisons in terms of district or area to inform comparison with information about the environment and resource availability. [This grouping] will offer a better comparison of result due to influences of environment, expertise and distribution of resources [which] differs from area to area. (School 4, English, Round 2).

It was also suggested that the reports note the Revised National Curriculum outcomes to show the link between the curriculum and the skills assessed. Additional information could also be included in the reports higlighting trends across the various schools as well as additional demographic characteristics of schools such as number of home-language learners, pre-school attendance of learners and number of repeating learners.

Currently, reports are only produced in English. Some schools suggested that the reports be provided in both Afrikaans and English. This raised the issue of reports being made available in Sepedi. The cost and labour implications of reports in all three languages are however large and schools indicated that while this would be good, it is not a main priority in terms of improvement. A consideration of reporting through the use of electronic reports which allows the schools to perform their own further analysis, was proposed by a secondary school. Reports should be in cd form (School 1, English, Round 1).

An idea was put forward that multiple copies of the reports be provided to schools so both the principal and educators would have copies readily available. A few schools indicated this would be useful, while the majority of schools indicated it was not necessary. Some schools expressed concern that educators might think that the two reports supplied differ which would cloud the process with doubt. One school indicated that the principal would prefer controlling the data and decide what information should be provided to educators. This is a school management issue. (School 4, English, Round 2). Half of the schools indicated that they felt the reports were relevant and appropriate for their needs. A request was made to ensure the turn-around time for the reports be shortened, to allow educators more time to alter their planning and practices according to the results.

Several recommendations related to the improvement of support to schools were made. Many schools have difficulty with consent from parents for the assessments as learners often do not convey the messages, or the parents are not accessible. To ensure consent, it was suggested that the consent letters for assessment be sent out to educators the year before testing. Then when parents register learners for schooling, they sign the forms. Many learners have to be reminded all the time. This would be a faster way of getting forms back. (School 23, English, Round 2). The idea enjoyed great support and schools added that it would have the additional benefit of informing the planning of the school calendar which can take testing dates into consideration.

Schools across the board agreed with the idea of giving information and supporting preschools and schools for preparing learners for the move into primary or secondary education. The idea of providing workshops for educators already involved in the project met with some ambivalence as some welcomed the suggestion, but others did not feel the need. Some schools, however, expressed the need for intervention materials to help support individual atrisk learners identified in reports. Intervention - methods for individuals-both problematic [learners] and [for] stimulating gifted learners. Will this be available sometime? (School 12, English/Afrikaans, Round 1) 
It was suggested that educators be allowed to observe fieldwork. Schools noted that this would allow educators to build confidence in the assessment and see how well the fieldworkers build rapport with the children. Educators will be able to judge learner's reaction towards an unknown person as some learners don't simply respond to a strange face as learner is familiar to educator. (School 23, English, Round 2) It was also mentioned that the educator presence may have a reassuring effect on learners, especially those new to schooling. Whilst schools advocated for observations of assessments, they added that this should be an opportunity to be extended, but not a requirement as it may be time consuming for educators.

A useful conceptualisation on how data should be provided is that the data has to speak to a measurable attribute, and different reference levels need to be included for stakeholders to make sense of the data. Information on different levels and years of administration need to be provided to the stakeholders and should be followed by a discussion on the discrepancies in years of administration which may be present. What is clear is that there has to be an additional step for researchers to engage in and this step entails what interventions can be put in place. It is important to identify strengths and weaknesses in learner abilities but it is vital to provide information and guidance on how the weaknesses can be addressed and how the strengths can be built upon. The impact of the data provided to schools and the use thereof is dependent on the ability to engage in complex behaviour tasks and this has to be facilitated with care in order to obtain the buy-in of stakeholders as well as their commitment and collaboration.

\section{Conclusions}

Perhaps the expectation of instrumental use as part of the data-driven decision making process is unrealistic as the effective use of performance information is a gradual process especially within the context of South Africa. Therefore, it is important for researchers to uncover obvious and less obvious examples of use. To this end, methods should be used which distinguish between partial and complete use and therefore deeper exploration and understanding of the behaviour of participants in terms of the complex process behind data use is needed (Beyer \& Trice, 1982).

The needs analysis, incorporating interviews, and the DEPHI technique elicited rich data with similar ideas emerging from both primary and secondary schools, probably because the focus was on transition periods of schooling. Overall, schools felt the process of feedback implemented was fit for the purpose intended. However, some schools felt that additional information could be provided. This suggestion is contrary to the expert review and findings from literature, which suggest streamlining and focusing information. There is evidence that schools are engaging with the information; however, the extent of actual usage of the information, and associated factors, in terms of instrumental, symbolic and conceptual use, still needs to be investigated.

\section{References}

Babbie, E., \& Mouton, J. (2001). The practice of social research. Cape Town: Oxford University Press.

Beyer, J. M. (1997). Research utilization: Bridging the gap between communities. Journal of Management Inquiry, 6, 17-22. 
Beyer, J. M., \& Trice, H. M. (1982). The utilization process: A conceptual framework and synthesis of empirical findings. Administrative Science Quarterly, 27 (4), 591-622

Bosker, R. J., Branderhorst; E. M., \& Visscher, A. J. (2007). Improving the utilisation of management information systems in secondary schools. School Effectiveness and School Improvement, http://0www.informaworld.com.innopac.up.ac.za/smpp/title $\sim$ content $=\mathrm{t} 714592801 \sim \mathrm{db}=\mathrm{all} \sim \mathrm{ta}$ $\mathrm{b}=$ issueslist branches $=18-\mathrm{v} 1818$ (4), $451-467$.

Brinko, K. T. (1993). The practice of giving feedback to improve teaching: What is effective? The Journal of Higher Education, 64 (5), 574-593.

Coe, R., \& Visscher, A. J. (2002). Introduction. In A. J. Visscher \& R. Coe (Eds.), School improvement through performance feedback (pp. 1-3). Lisse: Swets \& Zeitlinger Publishers.

Davenport, T. H., \& Prusak, L. (1998). Working knowledge: How organizations manage what they know. Boston: Harvard Business School Press.

Dunham, B.R. (1995). The DELPHI technique. Retrieved May 5, 2008 from http://www.medsch.wisc.edu/adminmed/2002/orgbehav/DELPHI.pdf.

Dunn, K. E., Airola, D. T., Lo, W., \& Garrison, M. (2012). What teachers think they can do with data: Development and validation of the data-driven decision making efficacy and anxiety inventory. Contemporary Educational Psychology, 38 (1), 87-98.

Dunn, K. E., Airola, D. T., Lo, W., \& Garrison, M. (2013). Becoming data-driven: The influence of the teachers' efficacy on concerns related to data-driven decision making. The Journal of Experimental Education, 81 (2), 222-241.

Estabrooks, C. A. (1999). The conceptual structure of research utilization. Research in Nursing \& Health, 22, 203-216.

Gawe, N., \& Heyns, R. (2004). Quality assurance. In J.G. Maree \& W.J. Fraser (Eds.), Outcomes-based assessment (pp.159-184). Sandown: Heinemann Publishers.

Harnar, M. A., \& Preskill, H. (2007). Evaluator's descriptions of process use: An exploratory study. New Directions for Evaluation 116, 27 - 44.

Heylighen, F. (1998). Basic concepts of the systems approach. Retrieved June 4, 2002, from http://pespmc1.vub.ac.be/SYSAPPR.html.

Illinois institute of technology (ND). The DELPHI method: Definition and Historical Background. Retrieved May 5, 2008 from http://www.iit.edu/ it/DELPHI.html

Kean, M. H. (1983). Administrative uses of research and evaluation information. Review of Research in Education, 10, 361-414.

Kirkhart, K. E. (2000). Reconceptualizing evaluation use: An integrated theory of influence. New Directions for Evaluation, 88, 5-23.

Light, D., Wexler, D., \& Heinze, J. (2004). How practitioners interpret and link data to instruction: Research findings on New York City schools' implementation of the grow network. Paper presented at the annual meeting of the American Educational Research Association, San Diego, CA.

Lincoln, Y. S., \& Guba, E. G. (1985). Naturalistic inquiry. London: Sage Publications. 
Love, J.M. (1985). Knowledge transfer and utilization in education. Review of Research in Education, 12, 377-386.

Luyten, H., Visscher, A., \&Witziers, B. (2005). School effectiveness research: From a review of criticism to recommendations for further development. School Effectiveness and School Improvement, 16(3), 249-279.

Mandinach, E. B., Honey, M., \& Light, D. (April, 2006). A theoretical framework for datadriven decision making. Paper presented at the annual meeting of the American Educational Research Association, San Francisco.

Mandinach, E.B. (2012). The perfect time for data use: Using data-driven decision making to inform practice. Educational Psychologist, 47 (2), 71-85.

Michigan State University Extension (1994). DELPHI technique. Retrieved May 5, 2008 from http://web1.msue.msu.edu/msue/imp/modii/iii00006.html

Morse, J. (2003). Principles of mixed methods and multimethod research design. In A. Tashakkori \& C. Teddlie (Eds.), The handbook of mixed methods in the social and behavioural research (pp. 189-208). London: Sage Publications.

Neuman, W.L. (1997). Social research methods: Qualitative and quantitative approaches. Boston: Allyn and Bacon.

Nieveen, N. (2009). Formative evaluation in educational design research. In T Plomp \& N. Nieveen (Eds.), An Introduction to Educational Design Research, pp 89-102. Enschede:SLO.

Organisation for Economic Co-operation and Development (OECD). (2005). School factors related to quality and equity: Results from PISA 2000. Retrieved July 26, 2005, from http://www.oecd.org/dataoecd/15/20/34668095.pdf.

Plomp, T. (2009). Educational design research: An introduction. In T Plomp \& N. Nieveen (Eds.), An Introduction to Educational Design Research, pp 9-36. Enschede:SLO.

Scientific Software Development. (1997). Atlas.ti the knowledge workbench: Short user's manual. Berlin: Thomas Muhr.

The Design-Based Research Collective. (2003). Design-based research: An emerging paradigm for educational inquiry. Educational Researcher 32 (1), 5-8.

Tindall, C. (1990). Issues of evaluation. In P. Banister, E. Burman, I. Parker, M. Taylor and C. Tindall (Eds.), Qualitative methods in psychology: A researchers guide (pp. 142-159). London: Sage Publishers.

United Nations Children's Fund (UNICEF). (2000). Defining quality in education. New York: United Nations Children's Fund.

Van der Werf, G., Creemers, B., \& Guldmond, H. (2001). Improving parental involvement in primary education in Indonesia: Implications, effects and costs. School Effectiveness and School Improvement, 12(4), 447-466.

Van Petegem, P., \& Vanhoof, J. (2005). Feedback of performance indicators: A tool for school improvement? Flemish case studies as a starting point for constructing a modle for school feedback. Revista Eletronca Iberoamericana sobre Calidad, Eficacia y Cambio en Educación, 3(1), 222-234. Retrieved January 30, 2007, from http://www.ice.deusto.es/rinace/reice/vol3n1_e/VanPetegemVanhoof.pdf. 
Visscher, A. J. (2002). A framework for studying school performance feedback systems. In A. J. Visscher and R. Coe (Eds.), School improvement through performance feedback (pp. 41-72). Lisse: Swets \& Zeitlinger Publishers.

Weber, R. P. (1985). Basic content analysis. London: Sage Publications.

Williams, K. (1999). Mixed quantitative and qualitative evaluation tools: A pragmatic approach. Retrieved March 17, from http://www.cemcentre.org/Documents/CEM\%20Extra/EBE/EBE1999/Kevin\%20 Williams.pdf.

Williams, P.L., \& Webb, C. (1994). The DELPHI technique: a methodological discussion. Journal of Advanced Nursing,19, 180-186.

Willig, C. (2001). Introducing qualitative research in psychology: adventures in theory and method. Philadelphia: Open University Press. 